\title{
Trial of Bronchodilator Drugs Given by Metered Aerosol with a Comparison of Two Bedside Methods of Estimating Airway Resistance
}

\author{
B. I. HOFFBRAND,* M.A., B.M., M.R.C.P. ; M. I. HOFFBRAND,* M.B., B.s.; I. D. HILL, $\dagger$ B.SC. \\ P. J. D. HEAF,* M.D., F.R.C.P.
}

Brit. med. F., 1966, 1, 1014-1016

The most popular current method of inhalation bronchodilator therapy in asthma and bronchitis is by dry aerosol, stored in small cartridges under pressure and delivered in metered doses. There is evidence that this method is superior to conventional wet aerosol inhalation in delivering an effective dose with greater economy (Bouhuys, 1963 ; Feinmann and Newell, 1963).

This paper reports a comparison of three proprietary dry aerosol bronchodilator products and a placebo of inert propellant. The active drugs were isoprenaline sulphate (Medihaler-iso-Forte) and two newer preparations-Bronchilator and orciprenaline (Alupent).

Bronchilator is a triple combination of two sympathomimetic amines (isoetharine and phenylephrine) and an antihistamine (thenyldiamine). The sympathomimetic amine isoetharine was found to be as effective as $1 \%$ isoprenaline without producing systemic upsets (Herschfus et al., 1951). It is an effective antagonist of histamine-induced bronchoconstriction in the guinea-pig, an action that is enhanced by the addition of the antihistamine thenyldiamine hydrochloride (Lands et al., 1958). The triple aerosol has been shown to be of value in asthma and to be largely free of side-effects (Spielman, 1961 ; Goldfarb and Romanoff, 1962; Siegel, 1962). The British reports to date have confirmed the value of this preparation in both asthma and bronchitis (El-Shaboury, 1964 ; Jacobsen and Prime, 1964).

Orciprenaline (Alupent), an analogue of isoprenaline, has been shown to be an effective bronchodilator when given by tablet, injection, or conventional wet aerosol (Zidek, 1961; Günthner, 1961; Myers and Coltman, 1963; Kennedy and Jackson, 1963 ; Edwards, 1964). The above reports suggest that orciprenaline is superior to isoprenaline in being less toxic and in having a more prolonged action. There is little known, however, about the comparative effectiveness of orciprenaline given as the metered dry aerosol.

In addition, this investigation was planned to compare two instruments commonly used for estimating airway resistance at the bedside and in the consulting-room. These are the peak-flow meter and the portable bellows spirometer.

\section{Methods}

There are 24 different orders in which four preparations can be given, and we decided to use 24 patients so as to balance the design of the trial by using each possible order once. Within the balanced design the selection of which patient had which order of treatments was determined at random.

The four preparations were given on separate, not necessarily consecutive, days. The cartridges were identical in appearance and the contents unknown to the patients. Each daily trial was started between 9 and 10 a.m. to avoid the fluctuation in airway resistance that is known to occur throughout the day (Lewinsohn et al., 1960). The lung-function tests

* University College Hospital.

† Statistica! Research Unit, Medical Research Council. were performed with the patients sitting, in a chair or in bed, both before and 3 to $5,15,30,60,120$, and 180 minutes after the aerosol inhalation. The manufacturers of the three active preparations all recommend one or two valve releases in practice. For the purposes of the trial we used inhalations from three separate valve releases, which gave doses as follows :

1. Isoprenaline sulphate $1.20 \mathrm{mg}$. A large dose was used to provide a critical yardstick against which to measure the effect of the newer preparations.

2. Bronchilator $1.35 \mathrm{mg}$. (isoetharine $1.05 \mathrm{mg}$, phenylephrine $0.21 \mathrm{mg}$., and thenyldiamine $0.09 \mathrm{mg}$.).

3. Orciprenaline $2.25 \mathrm{mg}$.

\section{Lung-function Tests}

Forced expiratory volume in one second (F.E.V.) and forced vital capacity (F.V.C.) were measured on a portable bellows spirometer ${ }^{1}$ (Horton and Phillips, 1959). The peak expiratory flow-rate (P.F.R.) was measured with a Wright Peak Flow Meter (Wright and McKerrow, 1959). In each case the values of three technically satisfactory results were recorded, the spirometer being always used before the peak-flow meter.

\section{Subjects}

These were 24 in-patients ${ }^{\circ}$ ith known airway obstruction, of whom, clinically, 18 had asthma, four chronic bronchitis, and two a combination of these conditions. Eight were male (aged 26 to 71 years) and 16 female (aged 29 to 68 years). There was a wide range of degree of reversibility of airway obstruction. During the period of the trial each patient continued previous oral drug therapy, which was altered as clinically indicated, but all routine inhalation therapy was stopped.

\section{Analysis}

The analysis was performed by the Atlas computer of the University of London. A separate analysis was made for each of the fixed times after inhalation at which tests were performed, except 180 minutes, where there were too many missing observations.

Several analyses were carried out for each time-namely, for each of the three measures of lung function (F.E.V., F.V.C., and P.F.R.), and for both the mean and the maximum of three observations. The figure used in each case was the ratio of the observed value (mean or maximum) at the specified time to the value (mean or maximum) immediately before inhalation.

Each analysis consisted of an analysis of variance in which the observed variability was split into parts depending upon the differences between patients, differences between daysthat is, first, second, third, or fourth day for the particular

${ }^{1}$ Vitalor (McKesson Instrument Co., Doncaster, Yorks). 
patient-differences between preparations, and the residual variability not explained by any of these factors. Tests of significance were then performed using the F-test.

\section{Results}

Differences between days were nowhere significant $(P>0.1$ in all cases), and it is concluded that the order of giving the preparations had no important effect.

There were no appreciable differences between the results of analysis using the mean of three observations and using the maximum of three observations. Judged by this trial neither method had any noticeable advantage over the other.

The F.E.V., F.V.C., and P.F.R. each produced a very similar pattern for the results, but the P.F.R. produced the pattern much more clearly, showing considerably bigger differences between preparations but almost the same standard error (see Table). In other words, the P.F.R., while telling the same story about the preparations, distinguished between them much more clearly. The F.E.V. came out better than the F.V.C. in this respect.

\begin{tabular}{|c|c|c|c|c|}
\hline Preparation & $\begin{array}{l}\text { Minutes after } \\
\text { Inhalation }\end{array}$ & F.E.V. & F.V.C. & P.F.R. \\
\hline Isoprenaline sulphate & $\begin{array}{r}3-5 \\
15 \\
30 \\
60 \\
120 \\
\end{array}$ & $\begin{array}{r}28 \cdot 5 \\
25 \cdot 0 \\
20 \cdot 3 \\
10 \cdot 5 \\
5 \cdot 4\end{array}$ & $\begin{array}{r}20 \cdot 8 \\
19 \cdot 1 \\
16 \cdot 2 \\
10 \cdot 5 \\
6.8\end{array}$ & $\begin{array}{r}47 \cdot 0 \\
43 \cdot 2 \\
35 \cdot 1 \\
17 \cdot 1 \\
9 \cdot 4 \\
\end{array}$ \\
\hline Bronchilator .. & $\begin{array}{r}3-5 \\
15 \\
30 \\
60 \\
120 \\
\end{array}$ & $\begin{array}{r}12.8 \\
12.1 \\
9.0 \\
3.7 \\
9.8 \\
\end{array}$ & $\begin{array}{r}14 \cdot 1 \\
14 \cdot 2 \\
9 \cdot 1 \\
7 \cdot 6 \\
15 \cdot 6 \\
\end{array}$ & $\begin{array}{l}22 \cdot 6 \\
22 \cdot 7 \\
17 \cdot 0 \\
12 \cdot 6 \\
14 \cdot 0 \\
\end{array}$ \\
\hline Orciprenaline & $\begin{array}{r}3-5 \\
15 \\
30 \\
60 \\
120 \\
\end{array}$ & $\begin{array}{l}17.6 \\
12.6 \\
15.5 \\
15.2 \\
15 \cdot 1 \\
\end{array}$ & $\begin{array}{l}14 \cdot 6 \\
13.8 \\
13.6 \\
12.1 \\
15 \cdot 0 \\
\end{array}$ & $\begin{array}{l}29 \cdot 0 \\
23 \cdot 0 \\
25 \cdot 5 \\
25 \cdot 7 \\
26 \cdot 1\end{array}$ \\
\hline Placebo & $\begin{array}{r}3-5 \\
15 \\
30 \\
60 \\
120 \\
\end{array}$ & $\begin{array}{r}-0.8 \\
2.5 \\
-2.2 \\
0.6 \\
8.2 \\
\end{array}$ & $\begin{array}{r}-2.1 \\
1.0 \\
0.3 \\
2.3 \\
8.1 \\
\end{array}$ & $\begin{array}{r}-4.4 \\
-5.8 \\
-3.3 \\
0.8 \\
0.9 \\
\end{array}$ \\
\hline Standard error & & $4 \cdot 3$ & $3 \cdot 7$ & $5 \cdot 1$ \\
\hline
\end{tabular}

Differences between patients (as judged by the P.F.R. mean values) were not significant up to 30 minutes after inhalation $(P>0.1)$, but just reached significance at 60 minutes $(P=0.05)$, and were highly significant at 120 minutes $(0.005>\mathrm{P}>0.001)$. This means that, though all the patients' readings changed initially by approximately the same percentage for a given preparation, some were still increased at two hours but others were not. There was no correlation between the percentage change two hours after inhalation and the initial reading.

Differences between preparations (again as judged by the P.F.R. mean values) were highly significant at all stages $(0.001>\mathrm{P}$ at 3 to 5 minutes, 15 minutes, and 30 minutes; $0.005>\mathrm{P}>0.001$ at 60 minutes and 120 minutes). The figure shows that isoprenaline was clearly the most effective in the short term, showing an average reading at 3 to 5 minutes up by $47 \%$. However, the bronchodilator effect had lost significance at about 70 minutes. Orciprenaline was by far the most effective in the longer term, the average reading being up by $26 \% 120$ minutes after inhalation. Figures for 180 minutes are not complete, but for orciprenaline figures are available for 11 of the 24 patients, and good estimates, derived from readings taken near 180 minutes, are available for 12 more. Using these 23 results, the average improvement was still $24 \%$ even after this length of time. Bronchilator was not as effective as isoprenaline or orciprenaline either in the short term or over a longer period. The bronchodilator effect of this preparation was no longer significant about 50 minutes after inhalation. The placebo preparation did not produce any significant improvement at any stage.

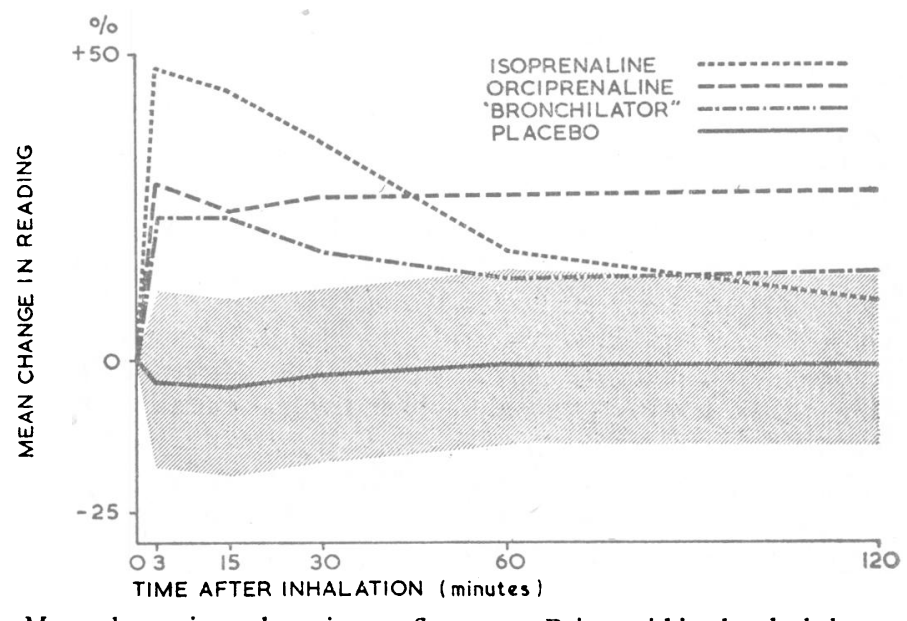

Mean change in peak expiratory flow-rate. Points within the shaded area are not significantly different from the placebo $(P>0.05)$.

No systematic attempt was made to evaluate side-effects, apart from asking each patient at the end of a morning's test what he thought about that morning's drug. Three patients complained of palpitations after isoprenaline and one of palpitations after orciprenaline. Bronchilator and the placebo gave rise to no symptoms.

\section{Discussion}

This investigation has shown that orciprenaline has a considerable long-acting bronchodilator effect when given by dry metered aerosol. The length of action of orciprenaline is far superior to that of a large dose of isoprenaline, while its shortterm effect bears favourable comparison with this drug. It should be noted, however, that there are marked differences, one hour and later after inhalation, between the responses of different patients. It cannot thus be assumed that orciprenaline will necessarily have a long-acting effect in an individual patient even though the short-term response is good.

We have confirmed that Bronchilator is an effective bronchodilator. El-Shaboury (1964) found that three inhalations of this preparation gave a dose more effective than an inhalation of isoprenaline equivalent to about $0.42 \mathrm{mg}$. of isoprenaline sulphate. We found such a dose less effective than $1.20 \mathrm{mg}$. of isoprenaline sulphate. Like other workers (Spielman, 1961 ; Goldfarb and Romanoff, 1962) we have found Bronchilator to be free of side-effects.

Most workers have found a fairly good correlation between P.F.R. and F.E.V. (Higgins, 1957 ; Lockhart et al., 1960 ; Ritchie, 1962). The F.E.V. is, however, probably more repeatable and more discriminatory in the diagnosis of airway obstruction (Fairbairn et al., 1962). Ritchie (1962) has suggested that the P.F.R. may be a more sensitive index than the F.E.V. in measuring change in airway resistance after bronchodilator therapy. Our findings confirm those of Ritchie in that the P.F.R. distinguished much more clearly than the F.E.V. between the various preparations. It is reasonable to deduce from this that the P.F.R. is a more sensitive measure than the F.E.V. of changes in airway resistance in the individual patient.

The portable bellows spirometer gives values similar to those of the conventional low resistance instrument (Horton and Phillips, 1959 ; McKerrow and Edwards, 1961). The peakflow meter is however cheaper and requires less co-operation from the patient than the portable spirometer and appears to 
be the preferable instrument for following changes in airway resistance in consulting-room and bedside practice.

\section{Summary}

A comparison has been made using lung-function tests of three proprietary bronchodilator preparations given by dry metered aerosol to 24 patients with asthma and chronic bronchitis.

Isoprenaline sulphate $(1.20 \mathrm{mg}$.) was found to be the most effective preparation for the first 30 to 45 minutes after inhalation. Though orciprenaline $(2.25 \mathrm{mg}$.) was less effective in the short term, it proved superior to isoprenaline in having a substantial bronchodilator effect three hours after inhalation. There was, however, considerable individual variation in the response.

Bronchilator, a combination of three separate drugs (total dose $1.35 \mathrm{mg}$.), was less effective than either orciprenaline or isoprenaline in the above doses.

The peak-flow meter was found to give a more sensitive index of changes in airway resistance after bronchodilator drugs than a portable bellows spirometer. We conclude that the peak-flow meter provides the method of choice when a convenient portable instrument for following changes in airway resistance is required.
We wish to thank Bayer Products Company, Boehringer Ingelheim Ltd., and Riker Laboratories for supplies of the preparations and secretarial help, and Miss A. Chamney for technical assistance.

\section{REFERENCES}

Bouhuys, A. (1963). Ned. T. Geneesk., 107, 1739.

Edwards, G. (1964). Brit. med. 7., 1, 1015.

El-Shaboury, A. H. (1964). Ibid., 2, 1037.

Fairbairn, A. S., Fletcher, C. M., Tinker, C. M., and Wood, C. H. (1962). Thorax, 17, 168 .

Feinmann, L., and Newell, D. J. (1963). Brit. F. Dis. Chest, 57, 140

Goldfarb, A. A., and Romanoff, A. (1962). Ann. Allergy, 20, 307.

Günthner, W. (1961). Arzneimittel-Forsch., 11, 525.

Herschfus, J. A., Bresnick, E., Levinson, L., and Segal, M. S. (1951). Ann. Allergy, 9, 769.

Higgins, I. T. T. (1957). Brit. med. ₹., 2, 1198.

Higgins, I. T. T. (1957). Brit. med. F., 2, 1198.

Horton, G. E., and Phillips, S. (1959). Amer. Rev. resp. Dis., 80,

Jennedy, M. C. S., and Jackson, S. L. O. (1963). Brit. med. F., 2, 1506.

Lands, A. M., Luduena, F. P., Hoppé, J. O., and Oyen, I. H. (1958). f. Amer. pharm. Ass. sci. Ed., 47, 744.

Lewinsohn, H. C., Capel, L. H., and Smart, J. (1960). Brit. med. fo, 1,

Lockhart, W., Smith, D. H., Mair, A., and Wilson, W. A. (1960). Ibid., $1,37$.

McKerrow, C. B., and Edwards, P. (1961). F. Amer. med. Ass., 177, 865.

Myers, W. H., and Coltman, R. S. (1963). Med. Dig. (Lond.), 8, 95

Ritchie, B. (1962). Lancet, $2,271$.

Ritchie, B. (1962). Lancet, 2, 271.

Siegel, C. (1962). f.-Lancet, 82, 461.

Wright, B. M., and McKerrow, C. B. (1959). Brit. med. F., 2, 1041.

Zidek, R. (1961). Therapiewoche, 11, 545.

\title{
Average Normal Values for the Forced Expiratory Volume in White Caucasian Males
}

\author{
J. E. COTES,* B.M., M.R.C.P. ; C. E. ROSSITER,* M.A., F.S.S. ; I. T. T. HIGGINS,*† M.D., M.R.c.P. \\ J. C. GILSON,* M.B., F.R.C.P.
}

Brit. med. F., 1966, 1, 1016-1019

The forced expiratory volume (F.E.V.) and other indices of ventilatory capacity have been measured and expressed as multiple regressions on age and height for healthy male subjects in many Western countries. The present paper reports the results of such an analysis for data obtained in the U.K. over the period 1957-64. The relationship is similar to others that have been reported. A number of these have therefore been combined to yield an overall regression which describes the average relationship of one second F.E.V. (F.E.V.. $)$ to age and height for healthy white Caucasian males in North-western Europe and North America. The relationship may be of use for predicting average normal values in communities where no direct measurements are available.

\section{Analysis of Some Data from the U.K.}

Using the apparatus described by McKerrow et al. (1960), members of this unit have measured the forced expiratory volume (F.E.V..$_{0.75}$ and F.E.V. ${ }_{1}$ ) and the forced vital capacity (F.V.C.) of men taken randomly from within defined communities in the United Kingdom and elsewhere. These surveys individually show that the F.E.V.s of smokers, after allowing for the effects of age, are less than those of non-smokers (Higgins, 1959). The F.E.V.s are also lower in those subjects who during the previous three years had persistent cough and phlegm and one or more chest illnesses severe enough to cause loss of time from work (Higgins et al., 1956).

We have now re-analysed the data for 405 men working in non-dusty occupations in three of these communities and one other, having first excluded all those who gave a history of chest illness or of undue breathlessness on exertion. In 113 subjects exclusion was made on the basis of an affirmative answer to either or both of two questions which are now included in the following form in the M.R.C. (1960) questionary on respiratory symptoms.

Question 21: During the past three years have you had any chest illness which has kept you off work, indoors, at home, or in bed ?

Question 14a: Are you ever troubled with shortness of breath when hurrying on the level or walking up a slight hill ?

Subjects who gave a negative response to these questions were not excluded on account of cough, sputum, or other symptoms except in nine instances when the symptoms were accompanied by a history of previous tuberculosis, pneumonia, or other notable chest illness. Eight subjects were excluded because their data were incomplete.

\footnotetext{
- Pneumoconiosis Research Unit of the Medical Research Council, Llandough Hospital, Penarth, Glamorgan.

t Present address: Department of Epidemiology, University of Pitto burgh, Pennsylvania 15213, U.S.A.
} 